\title{
Contribution of Selected Vasoactive Systems to Blood Pressure Regulation in Two Models of Chronic Kidney Disease
}

\author{
Natálie DRÁBKOVÁ ${ }^{1}$, Silvie HOJNÁ ${ }^{1}$, Josef ZICHA ${ }^{1}$, Ivana VANĚČKOVÁ ${ }^{1}$ \\ ${ }^{1}$ Laboratory of Experimental Hypertension, Institute of Physiology of the Czech Academy of \\ Sciences, Prague, Czech Republic
}

Received November 27, 2019

Accepted February 4, 2020

Epub Ahead of Print May 29, 2020

\section{Summary}

It is generally accepted that angiotensin II plays an important role in high blood pressure (BP) development in both 2-kidney-1clip (2K1C) Goldblatt hypertension and in partial nephrectomy (NX) model of chronic kidney disease (CKD). The contribution of sympathetic nervous system and nitric oxide to BP control in these models is less clear. Partial nephrectomy or stenosis of the renal artery was performed in adult (10-week-old) male hypertensive heterozygous Ren-2 transgenic rats (TGR) and normotensive control Hannover Sprague Dawley (HanSD) rats and in Wistar rats. One and four weeks after the surgery, basal blood pressure (BP) and acute BP responses to the consecutive blockade of renin-angiotensin (RAS), sympathetic nervous (SNS), and nitric oxide (NO) systems were determined in conscious rats. Both surgical procedures increased plasma urea, a marker of renal damage; the effect being more pronounced following partial nephrectomy in hypertensive TGR than in normotensive HanSD rats with a substantially smaller effect in Wistar rats after renal artery stenosis. We demonstrated that the reninangiotensin system does not play so fundamental role in blood pressure maintenance during hypertension development in either CKD model. By contrast, a more important role is exerted by the sympathetic nervous system, the activity of which is increased in hypertensive TGR-NX in the developmental phase of hypertension, while in HanSD-NX or Wistar-2K1C it is postponed to the established phase. The contribution of the vasoconstrictor systems (RAS and SNS) was increased following hypertension induction. The role of NO-dependent vasodilation was unchanged in 5/6 NX HanSD and in 2K1C Wistar rats, while it gradually decreased in 5/6 NX TGR rats.

\section{Key words}

Hypertension • Chronic kidney Disease • Vasoactive systems • Partial nephrectomy $\bullet$ Goldblatt hypertension

\section{Corresponding author}

I. Vaneckova, Laboratory of Experimental Hypertension, Institute of Physiology of the Czech Academy of Sciences, Videnska 1083, CZ-142 20, Prague 4, Czech Republic. Fax: +420241062488. E-mail: ivana.vaneckova@fgu.cas.cz

\section{Introduction}

Chronic kidney disease (CKD) is a lifethreatening disease which ultimately leads to a loss of kidney function. The main risk factors associated with CKD are hypertension, diabetes and obesity. Hypertension is one of the most important causes of CKD, which increases the extent of cardiovascular complications and leads to end-organ damage. The injured kidney loses the ability to properly regulate blood pressure, as well as water and sodium excretion, which finally leads to further aggravation of hypertension and CKD. Independent of the cause of renal insult, renal cells are damaged and inflammation develops, ultimately resulting in tissue fibrosis, damage to glomeruli and tubules and the loss of nephrons.

There are many different models of CKD. Among those with a relatively rapid development of CKD with accompanying hypertension and proteinuria, partial nephrectomy (Morrison, 1962), and 2-kidney-1clip (2K1C) Goldblatt hypertensive models (Goldblatt et al. 1934, Goldblatt et al. 1939) are very common. 
Gretz et al. (1988) analyzed CKD development in adult Sprague Dawley rats and found gradually increasing uremia with kidney function deterioration when the serum creatinine concentration reached $200 \mu \mathrm{g} / \mathrm{l}$. Thereafter, these rats usually died within 4-6 weeks, whereas the normotensive rats with lower creatinine levels survived 6-12 months after partial nephrectomy. By contrast, the development of CKD is more rapid in partially nephrectomized TGR - a model of angiotensin II-dependent hypertension, which was created by the introduction of murine Ren-2 gene into the genome of normotensive HanSD rats (Mullins et al. 1990). In these animals, blood pressure and proteinuria rose steeply within 2 weeks following 5/6 nephrectomy and the animals survived 4-6 months (Vaněčková et al. 2012, Čertíková et al. 2014, Sedláková et al. 2017). Moreover, during the developmental phase of hypertension, i.e. two weeks after 5/6 NX, renal angiotensin II and especially endothelin-1 levels were greatly increased (Sedláková et al. 2017) both being important features of the progression of CKD to end-stage renal damage.

In mice and rats, the hypertension development is quite rapid taking one or two weeks depending on the severity of renal artery occlusion and the age of the animals (Murphy et al. 1984, Kuneš 1993, Červenka et al. 2008). Following the clipping of the renal artery, the secretion of renin from kidney increases, resulting in the augmented plasma renin and angiotensin II concentrations (Navar et al. 1998). Huang et al. (1981) reported increased GFR as well as sodium and water excretion in the non-clipped kidney of Sprague-Dawley (SD) rats.

Using telemetry, blood pressure development following renal artery clip placement was analyzed in both mice and rats. In mice, Červenka et al. (2002) found that blood pressure started to increase three days after renal artery stenosis and reached a plateau after two weeks. The development of hypertension is slower in rats, taking one or two weeks (Bürgelová et al. 2009). Moreover, Walkowska et al. (2010) demonstrated in $2 \mathrm{~K} 1 \mathrm{C}$ rats that renal and plasma Angiotensin II concentrations were increased only in the developmental but not in the established stage, and were similar in the clipped and contralateral kidneys in the latter phase of hypertension development.

The chronic blockade of the renin-angiotensin system is effective in lowering of blood pressure in both CKD models. In fact, enalapril (ACE inhibitor) exerted antihypertensive effects that were similar to the combination of reserpine, hydralazine, and hydrochlorothiazide. However, only enalapril reduced proteinuria and glomerulosclerosis in Munich-Wistar rats after 5/6 nephrectomy (Anderson et al. 1986). By contrast, similar nephroprotective effects were reported when candesartan $\left(\mathrm{AT}_{1}\right.$ receptor blocker) was compared with the same triple therapy in 5/6 NX TGR rats (Kujal et al. 2010). Interestingly, enalapril was effective in the reduction of glomerulosclerosis in Sprague Dawley rats even in the established stage of CKD, i.e. when the treatment started 2 months after the nephrectomy (Adamczak et al. 2003). RAS blockade with losartan $\left(\mathrm{AT}_{1}\right.$ antagonist) and captopril (ACE inhibitor) also normalized BP in the $2 \mathrm{~K} 1 \mathrm{C}$ Goldblatt model while the administration of $\beta 1$-adrenoreceptor antagonist atenolol only partly reduced blood pressure (Ramos-Filho et al. 2014).

Sympathetic activity is increased in hypertension associated with chronic kidney disease (Campese 2014). Sympathetic activity measured as norepinephrine (NE) levels and the NE turnover rate were increased four weeks after nephrectomy in the posterior hypothalamic nucleus and locus coeruleus of 5/6 NX Sprague Dawley (SD) rats (Bigazzi et al. 1994). In addition, bilateral rhizotomy prevented the increase in NE levels following nephrectomy suggesting a role of SNS activation through the afferent innervation of kidneys in CKD development and maintenance (Campese et al. 1995a). Moreover, the same authors demonstrated the reduction of BP and glomerulosclerosis following rhizotomy in SD rats (Campese et al. 1995b). The reduction of BP, glomerulosclerosis and proteinuria was achieved not only by ACE inhibitor captopril but also by $\beta$ blocker carvedilol in SD rats after 5/6 nephrectomy (Brooks et al. 1993).

The increased sympathetic activity evaluated as low frequency (LF) of SBP (a frequency band indicating the level of sympathetic vasoconstrictor activity) together with substantially augmented heart rate was reported in 2K1C Wistar rats four weeks after clip placement (Oliveira-Sales et al. 2014). In addition, decreased cardiac baroreflex sensitivity, which arose already from the first week, correlated with hypertension development in this study. The involvement of sympathetic tone in Goldblatt hypertension was also documented by renal denervation, which resulted in the decrease of blood pressure while the opposite effect had unclipping of the renal artery, both procedures being followed by changes in plasma norepinephrine concentration (Katholi et al. 1982). 


\section{Material and Methods}

Male Wistar rats as well as Hannover Sprague Dawley (HanSD) and heterozygous Ren-2 transgenic rats (TGR) were housed at $23{ }^{\circ} \mathrm{C}$ under a $12 \mathrm{~h}$ light/dark cycle, fed a normal-salt diet $(0.45 \% \mathrm{NaCl})$ and given tap water ad libitum.

All procedures and experimental protocols were approved by the Ethical Committee of the Institute of Physiology, Czech Academy of Sciences, and conform to the European Convention on Animal Protection and Guidelines on Research Animal Use.

At the age of 10 weeks, partial nephrectomy or stenosis of the left renal artery were performed under anesthesia [Zoletil (Virbac, France; $8 \mathrm{mg} / \mathrm{kg}$ ) combined with Rometar (Bioveta, Czech Republic; $4 \mathrm{mg} / \mathrm{kg}$ ) intramuscularly, or Isoflurane (2.5\%), respectively]. Partial nephrectomy was achieved by the removal of the right kidney and both poles of the left kidney. A silver clip (internal diameter $0.2 \mathrm{~mm}$ ) was placed on the left renal artery, the right kidney was left intact. After one and four weeks following $5 / 6 \mathrm{NX}$ or $2 \mathrm{~K} 1 \mathrm{C}$, the acute experiments evaluating the contribution of major vasoactive systems to BP maintenance (vasoactive balance) were performed. One day prior to the experiment, two polyethylene cannulas were implanted under light isoflurane anesthesia (PE 50 for BP measurement in the left carotid artery, PE 10 for the infusion of drugs to the jugular vein) and the cannulas were exteriorized in the interscapular region. Blood pressure and its changes after the acute blockade of particular vasoactive systems were recorded using a pressure transducer and a multichannel recorder (ADInstruments, Bella Vista, Australia) in conscious animals $24 \mathrm{~h}$ later.

The consecutive steps of the blockade of distinct vasoactive systems were performed in conscious animals according to the modified protocol of Minami et al. (1995), which is regularly used in our laboratory (Kuneš et al. 2002, Vaněčková et al. 2012a). Briefly, after a 30-min recovery period (which is necessary for calming the animals after placing them in plastic measuring cages), baseline levels of systolic, diastolic, and mean arterial pressures were recorded for $15 \mathrm{~min}$. Then, a sequential blockade of renin-angiotensin system (RAS $10 \mathrm{mg} / \mathrm{kg}$ BW captopril), sympathetic nervous system (SNS - $5 \mathrm{mg} / \mathrm{kg}$ BW pentolinium), and nitric oxide synthase (30 mg/kg BW L-NAME) was performed. All these drugs were dissolved in saline and administered as intravenous bolus injections in a volume of $1 \mathrm{ml} / \mathrm{kg} \mathrm{BW}$.
Kidneys and hearts were weighed and plasma centrifuged (5000 x g for $10 \mathrm{~min}$ ) for further analysis. Plasma urea was measured using the Urea Assay Kit (Erba, Mannheim, Germany).

All drugs were purchased from Sigma (St. Louis, MO, USA).

Results are expressed as the mean \pm SEM. The statistical differences were evaluated by one-way analysis of variance (ANOVA) (Instat, La Jolla, CA, USA) followed by the appropriate post hoc test. Values of $\mathrm{p}<0.05$ were considered statistically significant.

\section{Results}

Partial nephrectomy in normotensive HanSD and hypertensive TGR rats

Partial nephrectomy removed $73 \%$ of the renal mass. This induced a plasma urea increase, which was doubled in HanSD rats and more than quadruplet in TGR at the end of the experiment (Fig. 1). This was followed by a compensatory hypertrophy of the remaining renal tissue, which was more pronounced in normotensive than in hypertensive rats (Table 1). Partial nephrectomy resulted in a reduction of body weight in both rat strains. There was a non-significant blood pressure increase following a nephrectomy in control HanSD rats (Fig. 2A). Strikingly, no BP increase was observed in TGR one week after the surgery whereas BP was substantially reduced four weeks after the partial nephrectomy. All 5/6 nephrectomized HanSD rats survived until the end of experiment. By contrast, a rapid decline in survival rates was observed during the first week after the surgery in hypertensive TGR animals with no further deterioration in mortality rates in the next three weeks (Fig. 3).

Captopril-induced blood pressure decrease (reflecting RAS-dependent vasoconstriction) (Fig. 2B) was augmented in the transgenic rats (TGR) compared to the control HanSD rats. We did not find any increase in RAS-dependent vasoconstriction in either rat strain in the developmental or the established phase of hypertension. The pentolinium-induced BP reduction (indicating the extent of sympathetic vasoconstriction) (Fig. 2C) was significantly greater in TGR than in HanSD rats. Its contribution to BP maintenance moderately increased in HanSD rats during the experiment, being statistically significant four weeks after 5/6 NX. By contrast, sympathetic vasoconstriction was highly increased in TGR after one week following surgery; however this was followed by its dramatic reduction at the end of the study. 
NO-dependent vasodilation was similar in the control HanSD and TGR rats during the study with one exception - its level was substantially reduced in TGR four weeks after 5/6 NX (Fig. 2D). The contribution of vasoconstrictor systems (the sum of RAS- and SNS-dependent vasoconstriction) to BP level was substantially augmented in TGR compared to HanSD rats (Fig. 4). Following nephrectomy, their contribution increased in both strains, while it dramatically dropped in TGR four weeks after NX. By contrast, the contribution of vasodilator NO system gradually decreased with time in both strains. We analyzed the correlation of major vasoactive systems with baseline blood pressure. There was an important correlation of MAP with RAS- and SNS-dependent vasoconstriction, while there was no correlation with NO-dependent vasodilation (Fig. 5).

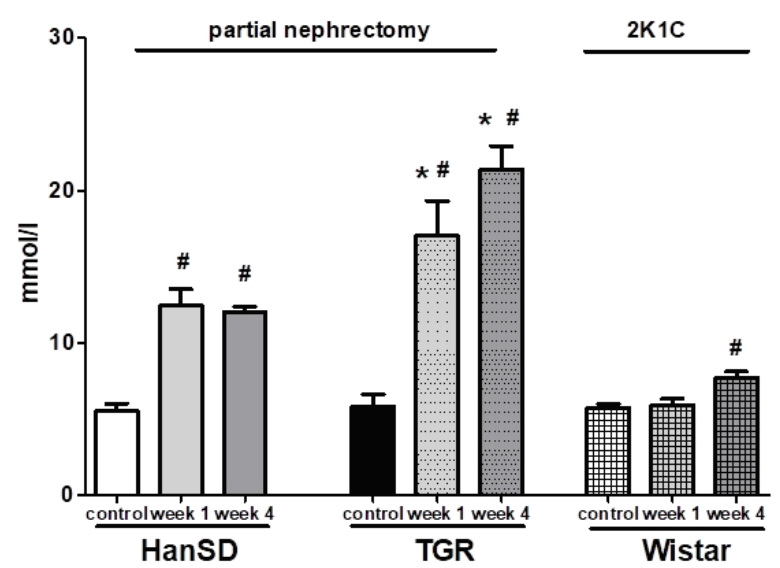

Fig. 1. Plasma urea in HanSD and heterozygous TGR under control conditions and after one or four weeks following partial nephrectomy (left panels) and in Wistar rats after the clipping of the renal artery (right panel). $* p<0.05$ vs. corresponding HanSD group, ${ }^{\#} p<0.05$ vs. control rats.

Table 1. Body, heart and kidney weights in normotensive Hannover Sprague Dawley (HanSD) and hypertensive Ren-2 transgenic rats (TGR) following partial nephrectomy.

\begin{tabular}{lcccccc}
\hline & \multicolumn{3}{c}{ HanSD } & & \multicolumn{2}{c}{ TGR } \\
& Control & NX week 1 & NX week 4 & Control & NX week 1 & NX week 4 \\
\hline Number of rats & 9 & 11 & 9 & 9 & 10 & 12 \\
Body weight $(g)$ & $496 \pm 8$ & $390 \pm 18^{\#}$ & $426 \pm 11^{\#}$ & $419 \pm 7^{*}$ & $378 \pm 8^{\dagger}$ & $345 \pm 13^{*, \#, \dagger}$ \\
Heart weight $(g)$ & $1.45 \pm 0.02$ & $1.37 \pm 0.03$ & $1.30 \pm 0.02^{\#}$ & $1.53 \pm 0.03^{*}$ & $1.48 \pm 0.02$ & $1.38 \pm 0.03^{\#}$ \\
$H W / B W(g / k g)$ & $290 \pm 4$ & $370 \pm 14^{\#}$ & $306 \pm 6^{@}$ & $367 \pm 7^{*}$ & $392 \pm 5^{\dagger}$ & $402 \pm 10^{@, \dagger}$ \\
$K W(g)$ & $2.04 \pm 0.03$ & $1.39 \pm 0.05^{\#}$ & $1.68 \pm 0.05^{\#, @}$ & $1.74 \pm 0.05^{*}$ & $1.31 \pm 0.05^{\#}$ & $1.40 \pm 0.07^{*, \#}$ \\
$K W / B W(g / k g)$ & $410 \pm 4$ & $363 \pm 17$ & $396 \pm 14$ & $415 \pm 8$ & $350 \pm 16^{\#}$ & $400 \pm 13^{@}$ \\
\hline
\end{tabular}

Data are means $\pm \mathrm{SEM},{ }^{*}$ vs. control rats of the same strain, ${ }^{*}$ vs. corresponding HanSD group, ${ }^{\dagger}$ vs. control HanSD rats, ${ }^{\circledR}$ week 4 vs. week 1.
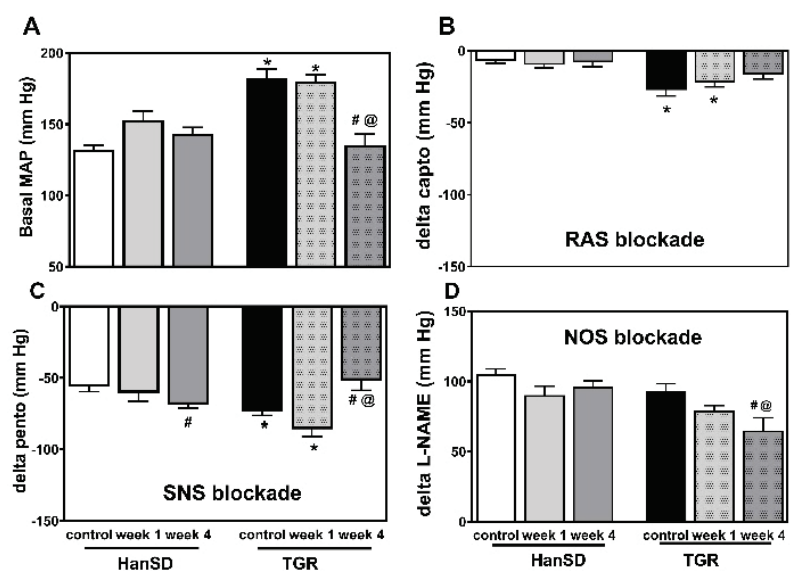

Fig. 2. Mean arterial pressure (MAP) (A) and changes to MAP as elicited by the sequential blockade of the renin-angiotensin system (RAS blockade by captopril) (B), the sympathetic nervous system (SNS blockade by pentolinium) (C) and nitric oxide synthase (NOS blockade by L-NAME) (D) in control HanSD as well as in TGR, and in rats one and four weeks after partial nephrectomy (NX). $* p<0.05$ vs. corresponding HanSD group, ${ }^{\#} \mathrm{p}<0.05$ vs. untreated TGR, ${ }^{\circledR} \mathrm{p}<0.05$ week 4 vs. week 1.

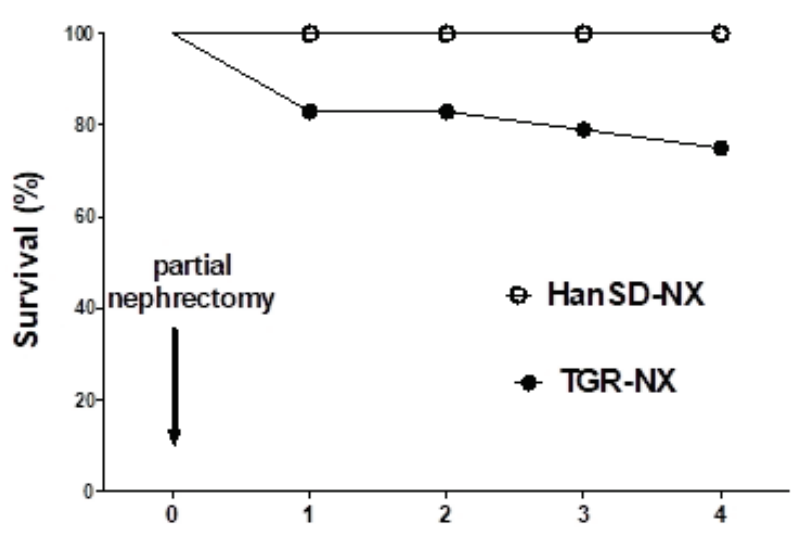

Fig. 3. Survival rate of HanSD and heterozygous TGR rats subjected to partial nephrectomy. 


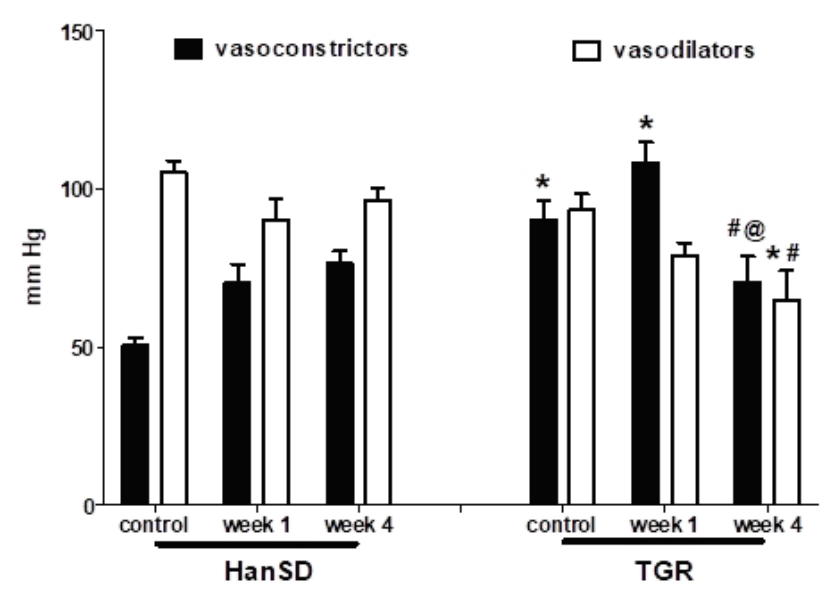

Fig. 4. The comparison of BP changes elicited by the blockade of the vasoconstrictor (RAS+SNS) and vasodilator (NO) systems in control HanSD and TGR, and in rats one and four weeks after partial nephrectomy (NX). * $\mathrm{p}<0.05$ vs. corresponding HanSD group, ${ }^{\#} \mathrm{p}<0.05$ vs. untreated TGR, ${ }^{\circledR} \mathrm{p}<0.05$ week 4 vs. week 1.
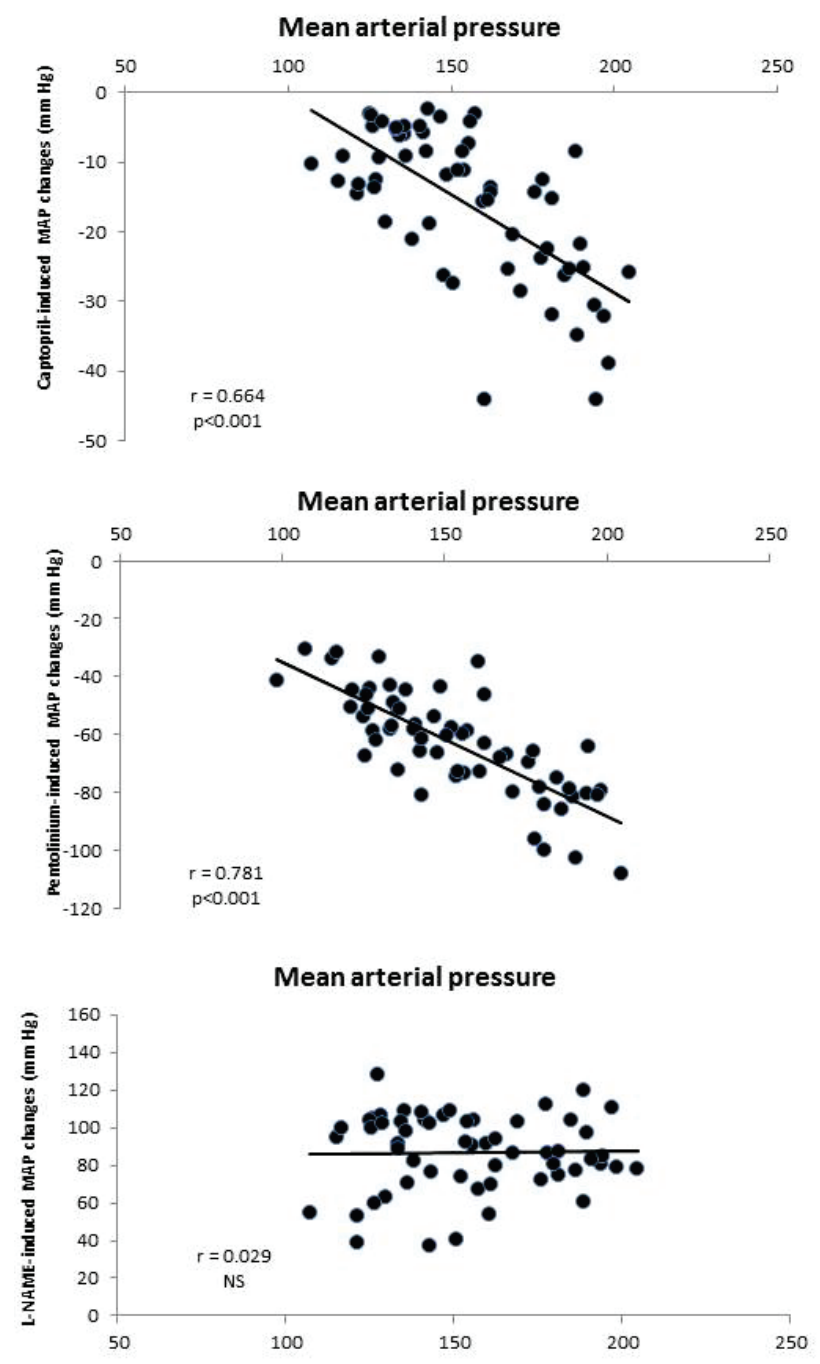

Fig. 5. The correlation of mean arterial pressure with RAS- and SNS-dependent vasoconstriction and with NOS-dependent vasodilation in HanSD $(n=29)$ and TGR $(n=31)$ animals.

\section{Goldblatt 2K1C hypertension in Wistar rats}

The development of renal damage following the clipping of the renal artery was documented by a slight increase in plasma urea at the end of the study; this parameter being substantially smaller in $2 \mathrm{~K} 1 \mathrm{C}$ rats than in animals, which underwent partial nephrectomy (Fig. 1 - right panel). All animals survived until the end of the study. There was a rapid increase in mean arterial pressure one week following $2 \mathrm{~K} 1 \mathrm{C}$ which persisted for the remaining three weeks (Fig. 6A). This was accompanied by an increase in heart weight at the end of the study (Table 2). While the clipped kidney tended to be smaller, the contralateral kidney was significantly heavier four weeks following the surgery.

Surprisingly, 2K1C had no effect on RASdependent vasoconstriction either one or four weeks after the clipping of the renal artery (Fig. 6B). By contrast, sympathetic vasoconstriction gradually increased and was significantly higher at the end of the study, while no difference in NO-dependent vasodilation occurred during the study (Fig. 6B, C). The contribution of the vasoconstrictor systems gradually increased after $2 \mathrm{~K} 1 \mathrm{C}$, whereas that of the vasodilator NO system remained stable (Fig. 7). The correlation analysis revealed an important relationship between MAP and sympathetic vasoconstriction (Fig. 8).
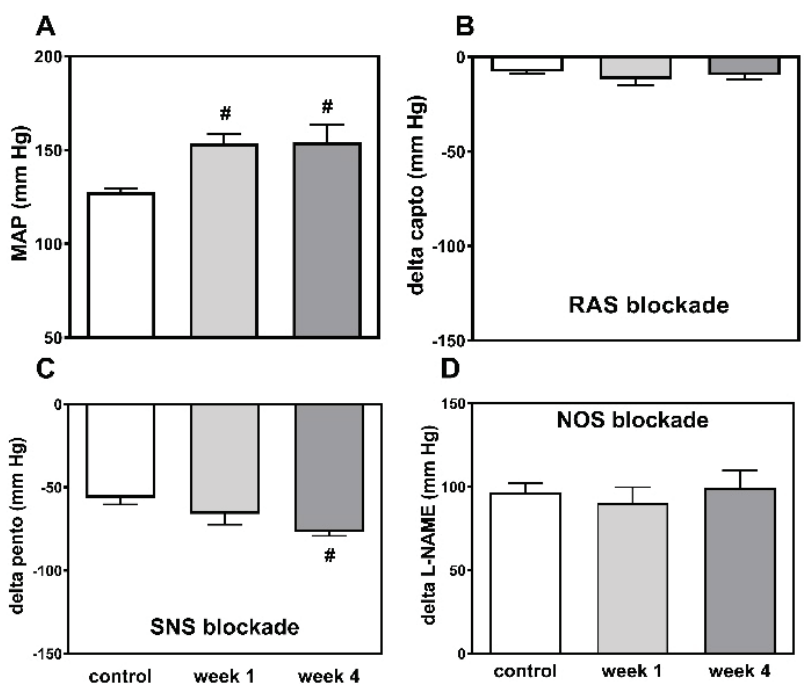

Fig. 6. Mean arterial pressure (MAP) (A) and its changes elicited by the sequential blockade of the renin-angiotensin system (RAS blockade by captopril) (B), the sympathetic nervous system (SNS blockade by pentolinium) (C) and nitric oxide synthase (NOS blockade by L-NAME) (D) in control Wistar rats and in Wistar rats one and four weeks following renal artery stenosis (2K1C). ${ }^{\#} \mathrm{p}<0.05$ vs. untreated Wistar rats. 
Table 2. Body, heart and kidney weights in control Wistar rats and in Wistar rats following renal artery stenosis (two-kidney-one-clip 2K1C).

\begin{tabular}{lccc}
\hline & Wistar-control & 2K1C-week 1 & 2K1C-week 4 \\
Number of rats & 13 & 11 & 8 \\
\hline Body weight $(g)$ & $463 \pm 10$ & $399 \pm 8^{\#}$ & $445 \pm 14^{@}$ \\
Heart weight $(g)$ & $1.10 \pm 0.03$ & $1.19 \pm 0.01$ & $1.326 \pm 0.05^{\#, @}$ \\
HW/BW $(\mathrm{g} / \mathrm{kg})$ & $240 \pm 4$ & $298 \pm 7^{\#}$ & $294 \pm 13^{\#}$ \\
Left $K W(g)$ & $1.56 \pm 0.05$ & $1.43 \pm 0.09$ & $1.4 \pm 0.09$ \\
Right $K W(g)$ & $1.59 \pm 0.06$ & $1.65 \pm 0.07$ & $2.03 \pm 0.11^{\#, @}$ \\
LKW/BW $(\mathrm{g} / \mathrm{kg})$ & $327 \pm 16$ & $355 \pm 18$ & $307 \pm 16$ \\
RKW/BW $(\mathrm{g} / \mathrm{kg})$ & $329 \pm 19$ & $411 \pm 14^{\#}$ & $448 \pm 19^{\#}$ \\
\hline
\end{tabular}

Data are means \pm SEM, ${ }^{\#}$ vs. control Wistar rats, ${ }^{\circledR}$ week 4 vs. week 1.

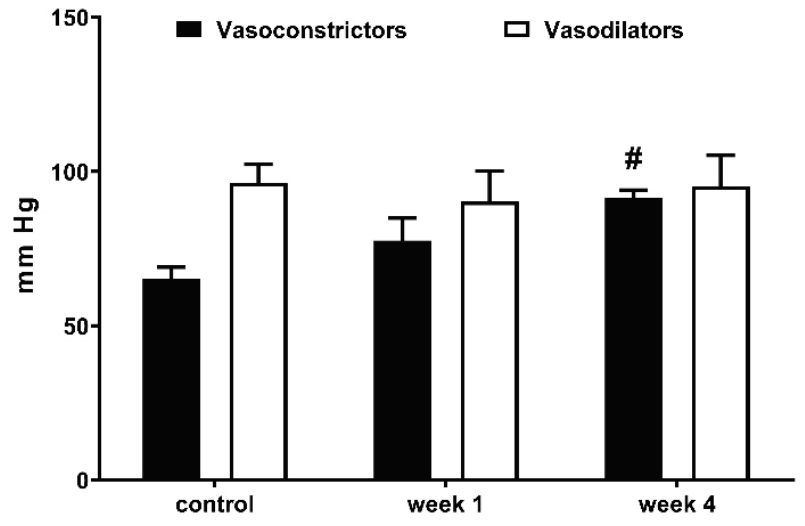

Fig. 7. The comparison of BP changes elicited by the blockade of the vasoconstrictor (RAS+SNS) and vasodilator (NO) systems in control Wistar rats, and in rats one and four weeks following renal artery stenosis $(2 \mathrm{~K} 1 \mathrm{C}) . * \mathrm{p}<0.05$ vs. corresponding HanSD group, ${ }^{\#} \mathrm{p}<0.05$ vs. untreated TGR rats, ${ }^{\circledR} \mathrm{p}<0.05$ week 4 vs. week 1.

\section{Discussion}

Our results confirmed that both reninangiotensin and sympathetic nervous systems contribute to the high blood pressure of TGR rats. This is consistent with our previous results (Vaněčková et al. 2012a) which demonstrated that RAS is more important in the developmental phase of this form of hypertension while later this role is taken by SNS. Thus, the decrease in BP after acute captopril administration (RAS-dependent vasoconstriction) was greater in 2-month-old than in 5-month-old TGR rats. By contrast, pentolinium-induced BP change (SNS-dependent vasoconstriction) was greater in the older TGR (Vaněčková et al. 2012a).

Partial nephrectomy caused only a mild, nonsignificant BP elevation in nephrectomized HanSD rats. This is consistent with the previous study of Bidani et al.
(1990) who demonstrated that after 5/6 nephrectomy, $75 \%$ of Wistar-Kyoto rats remained normotensive and without any glomerular damage. However, Kujal et al. (2010) reported an increase in BP of normotensive, partially-nephrectomized HanSD rats. This BP rise was, however, postponed, reaching a plateau after 6 weeks. Nevertheless, in hypertensive TGR they found a $40 \mathrm{~mm}$ $\mathrm{Hg}$ increase after partial nephrectomy which was not demonstrated in our present study (Kujal et al. 2010). In contrast, in the fourth week after NX, BP was decreased in our TGR rats. It is difficult to provide an explanation for this finding. One possibility is that the severity of CKD was higher in our study because during the first week after NX, almost $25 \%$ of TGR animals died, while in previous studies (Kujal et al. 2010, Vaněčková et al. 2012b), $100 \%$ of TGR and HanSD rats survived 1-3 months after surgery, depending on the rat strain.

A second possibility for the absence of BP increase following the nephrectomy in our study is the death of animals with the highest BP already during the first week after the surgery, either due to renal or cardiac failure. However, we did not analyze the cause of death in the present study. Nevertheless, Kujal and Vernerová (unpublished results) showed that half of the animals died from cardiac failure. The BP decrease observed in our TGR four weeks after the surgery was probably caused by the poor health condition of animals, who were in the malignant phase of CKD. This is also suggested by the survival rate curve which declines during the first week; this decline is much earlier than in other studies.

CKD development was also manifested by increased plasma urea which was higher in SD rats after nephrectomy as compared with control normotensive SD rats (Zicha et al. 1990). Plasma urea is further 
aggravated in partially nephrectomized TGR and very likely contributes to the worsening of their condition and their decreased survival rates.
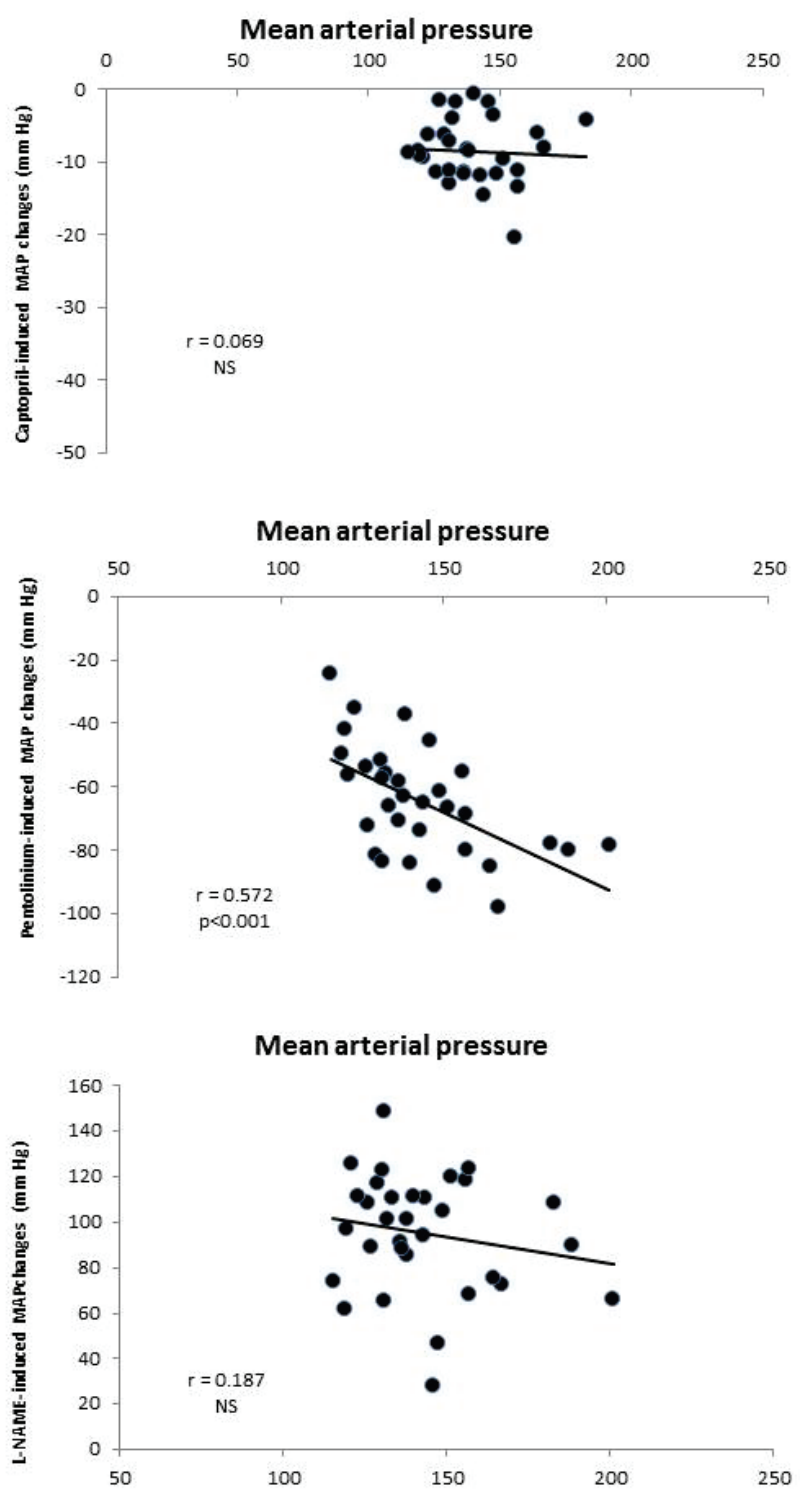

Fig. 8. The correlation of mean arterial pressure with RAS- and SNS-dependent vasoconstriction and with NOS-dependent vasodilation in control Wistar rats and in rats one and four weeks following renal artery stenosis $(2 K 1 C)(n=32)$.

The role of renin-angiotensin system in chronic kidney disease is supported by many studies demonstrating that the inhibitors of RAS (the combination of $\mathrm{ACE}$ inhibitors and $\mathrm{AT}_{1}$ receptor blockers) strongly decrease the BP in animals after a partial nephrectomy (Kujal et al. 2010, Vaněčková et al. 2012b, Kujal et al. 2014). In contrast to these studies suggesting an important role of RAS in CKD development, we did not find its role to be significant either in the developmental or established phases of CKD. By contrast, a more important role of SNS in both phases was demonstrated in the two studied models. The unexpected BP fall four weeks after NX could be ascribed to the substantial attenuation of sympathetic vasoconstriction in these animals. Nevertheless, Figures 4 and 7 clearly demonstrate that the contribution of vasoconstrictors (the sum of BP changes induced by captopril and pentolinium) increased following nephrectomy in both CKD models and contributed to higher BP. By contrast, a decrease of NO-dependent vasodilation might also contribute to hypertension development. Both vasoconstrictor systems (RAS and SNS) are substantially involved in BP maintenance in HanSD and TGR following partial nephrectomy as could be seen from significant correlations of basal BP with BP changes after the acute blockade of RAS or SNS (Fig. 5), while only SNS contribution correlated with baseline MAP in $2 \mathrm{~K} 1 \mathrm{C}$ hypertension. This is consistent with the observations that high angiotensin II concentrations are important for $2 \mathrm{~K} 1 \mathrm{C}$ hypertension only in the developmental phase (Walkowska et al. 2010).

Renal artery stenosis induced a significant increase in BP in Wistar rats after the first week following surgery, which persisted during the fourth week after clipping. This partially recalls the results in Sprague Dawley rats in Guan et al. (1992) who reported BP increase within first two weeks after 2K1C. Červenka et al. (2008) reported a maximal BP increase in HanSD rats within two weeks when the BP reached a plateau. Moreover, in the study of Bürgelová et al. (2009), the maximal level of BP was achieved one week after the clipping, which is highly consistent with our study. The increased BP is reflected in a greater cardiac hypertrophy at week four, while the worsening of kidney function is indicated by an increased plasma urea concentration.

Although the Goldblatt 2K1C model was primarily characterized by increased activity of the reninangiotensin system through the activation of the $\mathrm{AT}_{1}$ receptor by angiotensin II, there is evidence that the sympathetic nervous system also participates in this form of hypertension. Indeed, Walkowska et al. (2010) demonstrated the increased renal and plasma concentrations of angiotensin II one week after the clipping of the renal artery, while no differences between contralateral and clipped kidney were observed after four weeks. Conversely, Oliveira-Sales et al. (2014) found that the contribution of SNS is augmented from the $4^{\text {th }}$ week after clipping. Our results are only partly in 
agreement with these studies showing no change in RAS-dependent vasoconstriction either in the developmental or in the established phase of $2 \mathrm{~K} 1 \mathrm{C}$ hypertension. A more important role is played by sympathetic vasoconstriction which is largely accentuated especially at the $4^{\text {th }}$ week and it is only moderately increased in the developmental phase. This is consistent with the findings of Oliveira-Sales et al. (2014). The contribution of NO-dependent vasodilation remained at the same level in clipped animals as in the controls both in the developmental and established phase and did not contribute to BP changes following $2 \mathrm{~K} 1 \mathrm{C}$.

\section{Conclusions}

Although both examined forms of chronic kidney disease (partial nephrectomy and two-kidney-one- clip hypertension) were usually reported as models with augmented activity of the renin-angiotensin system, our results instead support the prevailing contribution of the sympathetic nervous system in BP maintenance during the developmental and established phases of CKD.

\section{Conflict of Interest}

There is no conflict of interest.

\section{Acknowledgements}

The technical assistance of Z. Kopecká and A. Charvátová is highly appreciated. This study was supported by the institutional support, grant Nr. RVO 67985823 and by the Czech Grant Agency, grant Nr. 19-06199S. The authors are grateful to Mr. R. Kotanchik for his help in editing the manuscript.

\section{References}

ADAMCZAK M, GROSS M-L, KRTIL J, KOCH A, TYRALLA K, AMANN K, RITZ E: Reversal of Glomerulosclerosis after high-dose enalapril treatment in subtotally nephrectomized rats. J Am Soc Nephrol 14: 2833-2842, 2003. https://doi.org/10.1097/01.asn.0000095248.91994.d3

ANDERSON S, RENNKE HG, BRENNER BM: Therapeutic advantage of converting enzyme inhibitors in arresting progressive renal disease associated with systemic hypertension in the rat. J Clin Invest 77: 1993-2000, 1986. https://doi.org/10.1172/jci112528

BIDANI AK, MITCHELL KD, SCHWARTZ MM, NAVAR LG, LEWIS EJ: Absence of glomerular injury or nephron loss in a normotensive rat remnant kidney model. Kidney Int 38: 28-38, 1990. https://doi.org/10.1038/ki.1990.163

BIGAZZI R, KOGOSOV E, CAMPESE VM: Altered norepinephrine turnover in the brain of rats with chronic renal failure. J Am Soc Nephrol 4: 1901-1907, 1994.

BROOKS DP, SHORT BG, CYRONAK MJ, CONTINO LC, DICRISTO M, WANG YX, RUFFOLO RR: Comparison between carvedilol and captopril in rats with partial ablation-induced chronic renal failure. British J Pharmacol 109: 581-586, 1993. https://doi.org/10.1111/j.1476-5381.1993.tb13610.x

BÜRGELOVÁ M, VAŇOURKOVÁ Z, THUMOVÁ M, DVOŘÁK P, OPOČENSKÝ M, KRAMER HJ, ŽELÍZKO M, MALÝ J, BADER M, ČERVENKA L: Impairment of the angiotensin-converting enzyme 2-angiotensin-(1-7)mas axis contributes to the acceleration of two-kidney, one-clip Goldblatt hypertension. J Hypertens 27 : 1988-2000, 2009. https://doi.org/10.1097/hjh.0b013e32832f0d06

CAMPESE VM, KOGOSOV E: Renal afferent denervation prevents hypertension in rats with chronic renal failure. Hypertension 25: 878-882, 1995a. https://doi.org/10.1161/01.hyp.25.4.878

CAMPESE VM, KOGOSOV E, KOSS M: Renal afferent denervation prevents the progression of renal disease in the renal ablation model of chronic renal failure in the rat. Am J Kidney Dis 26: 861-865, 1995 b. https://doi.org/10.1016/0272-6386(95)90456-5

CAMPESE VM: Pathophysiology of resistant hypertension in chronic kidney disease. Semin Nephrol 34: 571-576, 2014. https://doi.org/10.1016/i.semnephrol.2014.08.011

CERVENKA L, HORÁCEK V, VANECKOVÁ I, HUBÁCEK JA, OLIVERIO MI, COFFMAN TM, NAVAR LG: Essential role of AT1A receptor in the development of 2K1C hypertension. Hypertension 40: 735-741, 2002. https://doi.org/10.1161/01.hyp.0000036452.28493.74 
ČERVENKA L, VANĚČKOVÁ I, HUSKOVÁ Z, VAŇOURKOVÁ Z, ERBANOVÁ M, THUMOVÁ M, ŠKAROUPKOVÁ P: Pivotal role of angiotensin II receptor subtype 1A in the development of two-kidney, one-clip hypertension: study in angiotensin II receptor subtype 1A knockout mice. J Hypertens 26: 1379-1389, 2008. https://doi.org/10.1097/hjh.0b013e3282fe6eaa

GOLDBLATT H, KAHN JR, HANZAL RF: Studies on experimental hypertension: IX. The effect on blood pressure of constriction of the abdominal aorta above and below the site of origin of both main renal arteries. J Experim Med 69: 649-674, 1939. https://doi.org/10.1016/s0002-8703(39)90797-0

GOLDBLATT H, LYNCH J, HANZAL RF, SUMMERVILLE WW: Studies on experimental hypertension: I. The production of persistent elevation of systolic blood pressure by means of renal ischemia. J Exp Med 59: 347-379, 1934. https://doi.org/10.1084/jem.59.3.347

GRETZ N, MEISINGER E, STRAUCH M: Partial nephrectomy and chronic renal failure: The 'mature' rat model. Contrib Nephrol 60: 46-55, 1988. https://doi.org/10.1159/000414789

GUAN S, FOX J, MITCHELL KD, NAVAR LG: Angiotensin and angiotensin converting enzyme tissue levels in twokidney, one clip hypertensive rats. Hypertension 20: 763-767, 1992. https://doi.org/10.1161/01.hyp.20.6.763

KUJAL P, VERNEROVÁ Z: 5/6 nephrectomy as an experimental model of chronic renal failure and adaptation to reduced nephron number. (In Czech) Cesk Fysiol 57: 104-109, 2008.

KUJAL P, ČERTÍKOVÁ CHÁBOVÁ V, ŠKAROUPKOVÁ P, HUSKOVÁ Z, VERNEROVÁ Z, KRAMER HJ, WALKOWSKA A: Inhibition of soluble epoxide hydrolase is renoprotective in 5/6 nephrectomized Ren-2 transgenic hypertensive rats. Clin Exp Pharmacol Physiol 41: 227-237, 2014. https://doi.org/10.1111/1440$\underline{1681.12204}$

KUJAL P, ČERTÍKOVÁ CHÁBOVÁ V, VERNEROVÁ Z, WALKOWSKA A, KOMPANOWSKA-JEZIERSKA E, SADOWSKI J, VAŇOURKOVÁ Z: Similar renoprotection after renin-angiotensin-dependent and independent antihypertensive therapy in 5/6-nephrectomized Ren-2 transgenic rats: are there blood pressureindependent effects? Clin Exper Pharmacol Physiol 37: 1159-1169, 2010. https://doi.org/10.1111/j.1440$\underline{1681.2010 .05453 . \mathrm{x}}$

MORRISON AB: Experimentally induced chronic renal insufficiency in the rat. Lab Invest 11: 321-332, 1962.

MULLINS JJ, PETERS J, GANTEN D: Fulminant hypertension in transgenic rats harbouring the mouse Ren-2 gene. Nature 344: 541-544, 1990. https://doi.org/10.1038/344541a0

MURPHY WR, COLEMAN TG, SMITH TL, STANEK KA: Effects of graded renal artery constriction on blood pressure, renal artery pressure, and plasma renin activity in Goldblatt hypertension. Hypertension 6: 68-74, 1984. https://doi.org/10.1161/01.hyp.6.1.68

NAVAR LG, ZOU L, VON THUN A, TARNG WANG C, IMIG JD, MITCHELL KD: Unraveling the mystery of Goldblatt hypertension. News Physiol Sci 13: 170-176, 1998. https://doi.org/10.1152/physiologyonline.1998.13.4.170

OLIVEIRA-SALES, ELIZABETH B, TOWARD MA, CAMPOS RR, PATON JFR: Revealing the role of the autonomic nervous system in the development and maintenance of Goldblatt hypertension in rats. Auton Neurosc 183: 23-29, 2014. https://doi.org/10.1016/j.autneu.2014.02.001

VANĚČKOVÁ I, DOBEŠOVÁ Z, KUNEŠ J, ZICHA J: The effects of repeated delivery of angiotensin II AT1 receptor antisense on distinct vasoactive systems in Ren-2 transgenic rats: young vs. adult animals. Hypertens Res 35: 761, 2012a. https://doi.org/10.1038/hr.2012.29

VANĚČKOVÁ I, KUJAL P, HUSKOVÁ Z, VAŇOURKOVÁ Z, VERNEROVÁ Z, ČERTÍKOVÁ CHÁBOVÁ V, ŠKAROUPKOVÁ P, KRAMER HJ, TESAR̆ V, ČERVENKA L: Effects of combined endothelin A receptor and renin-angiotensin system blockade on the course of end-organ damage in 5/6 nephrectomized Ren-2 hypertensive rats. Kidney Blood Press Res 35: 382-392, 2012b. https://doi.org/10.1159/000336823

WALKOWSKA A, THUMOVÁ M, ŠKAROUPKOVÁ P, HUSKOVÁ Z, VAŇOURKOVÁ Z, ČERTÍKOVÁ CHÁBOVÁ V, TESAŘ V: Intrarenal CYP-450 metabolites of arachidonic acid in the regulation of the nonclipped kidney function in two-kidney, one-clip Goldblatt hypertensive rats. J Hypertens 28: 582-593, 2010. https://doi.org/10.1097/hjh.0b013e328334dfd4 
ZICHA J, KRONAUER J, DUHM J: Effects of a chronic high salt intake on blood pressure and the kinetics of sodium and potassium transport in erythrocytes of young and adult subtotally nephrectomized Sprague-Dawley rats. J Hypertens 8: 207-217, 1990. https://doi.org/10.1097/00004872-199003000-00002 